\title{
Comparison of Agility, Sprint, Anaerobic Power and Aerobic Capacities of Soccer Players by Playing Positions
}

\author{
Erkan Çetinkaya ${ }^{1}$, Halil Tanır ${ }^{1}$, Binnur Çelebi ${ }^{2}$ \\ ${ }^{1}$ Adnan Menderes University, Faculty of Sport Sciences, Aydın, Turkey. \\ ${ }^{2}$ Kastamonu University, School of Physical Education and Sport, Kastamonu, Turkey. \\ Correspondence: Erkan Çetinkaya, Adnan Menderes University, Faculty of Sport Sciences, Aydın, Turkey.
}

Received: May 24, 2018

doi:10.11114/jets.v6i9.3560
Online Published: August 20, 2018

URL: https://doi.org/10.11114/jets.v6i9.3560

\begin{abstract}
This study was carried out to compare the agility, sprint, anaerobic power and aerobic capacities of the soccer players by their playing positions. 33 male soccer players (defenders $(n=8) 20 \pm 1.73$ years; midfielders $(n=10) 20.09 \pm 1.97$ years forwards $(n=7) 20.55 \pm 1.91)$ with a training age of over 5 years playing in different positions in Kastamonu amateur league participated in the study voluntarily. First, Body Mass Index (BMI) values were calculated by measuring the height and weight of each player. Then, Illinois Agility Test, Yoyo Intermittent Recovery Test, $30 \mathrm{~m}$. Sprint Test and Running-Based Anaerobic Sprint Test (RAST) were conducted. Statistical analysis was done with the SPSS 22.0 program. No statistically significant differences were observed between defenders, midfielder and forwards in Yoyo Test (m.), $\mathrm{MaxVO}_{2}$ (ml/kg/min.), RAST maximal power, RAST average power and RAST fatigue index (p>0.05). However, a significant difference was found between players in Illinois Test (sec.) and $30 \mathrm{~m}$. Sprint Test (sec.) (p<0.05). Forwards and midfielders were more agile than defenders, and midfielders were faster than defenders. It will therefore contribute to their performance to evaluate physical and physiological needs according to playing positions as the distances players cover vary depending on their playing positions (defense, midfield and forward) along with the movements they perform on the pitch and the frequency of these movements.
\end{abstract}

Keywords: soccer, anaerobic power, aerobic capacity

\section{Introduction}

Soccer is a game which is played within its rules by a certain number of players in a limited area using all parts of the body except for the hands and the result is determined by the number of goals scored or conceded (Göral \& Göral 2015). Soccer is seen as the most popular sport in the world. It is a complex sports discipline in which aerobic and anaerobic energy systems are used and factors such as overall endurance and coordination affect performance (Sever, 2013). In addition, soccer is a sport which embodies physical performance characteristics such as agility, speed, power and strength, and is influenced by all these parameters (Hazir et al., 2010).

Agility is a physical characteristic required for a successful performance in soccer and it is equally important for other sports activities. Agility can also be defined as the control and coordination ability that enables the body and joints to be in the right position in space while quickly changing direction during a series of movements (Shephard \& Young 2006). Agility can be defined simply as the ability to change direction rapidly. In other words, it is the rapid whole body movement with change of direction in response to stimuli coming from the environment. Agility in soccer is the most fundamental performance component that determines the quality in players' movements such as rapid acceleration and deceleration and in their sprints which require quick change of direction. For this reason, it is necessary for the players to predict what they will do depending on the effect likely to arise and the decision they have made, and adjust the speed of their movement accordingly. Agility can be improved by techniques specific to sports. It has an effect on body position, ability to change direction and quick acceleration. There is a relationship between body position and the applied force; the body for example leans forward while accelerating, returns to its initial vertical position while decelerating and moves sideways during vertical displacements. These factors can also be perfected over time through training (Özdemir, 2013).

Sprint training generally aims to improve skills such as straight sprint acceleration which does not involve change of direction, achieving maximal speed and maintaining speed. It was found that straight sprint training does not have a 
significant effect on high-speed running performance involving change of direction, and that specific agility training does not improve straight sprint performance (Young et al., 2001). For this reason, the level of significance between straight sprint and agility (running speed with change of direction) is not as high as expected (Hazır et al., 2010).

Anaerobic performance largely includes explosive exercises that end in a short time. The immediate need for the energy for these types of efforts is provided by ATP-CP and anaerobic glycolysis. Anaerobic capacity is therefore the total amount of the energy that is obtainable from the anaerobic energy systems (Köklü et al., 2007). It is stated that anaerobic performance depends on two factors: anaerobic power and anaerobic capacity (Sutton et al., 2000). Of these two factors, anaerobic power depends on the use of alactacid energy system (ATP-PCr system) in relation to the ATP regeneration process in high-intensity, short-duration burst of efforts while anaerobic capacity is largely based on the use of the lactacid energy system (anaerobic glycolysis) (Bencke et al., 2002; Inbar \& Bar-Or 1986; Kearney et al., 2000; Müniroğlu et al., 2012).

In soccer, anaerobic power and capacity are needed to start running quickly, to run fast, to change the direction quickly, to head the ball, to jump high and to quickly swing the foot to kick the ball (Köklü et al., 2007).

In all sporting activities, the energy required for movement is generated through metabolic processes. All muscle contractions, whether voluntary or involuntary, require energy. Therefore, the primary source of this energy (ATP) is adenosine triphosphate. The energy produced can be used in any process, for example in metabolic conditions or for muscle contractions. Anaerobic threshold is the point at which energy metabolism starts to switch to anaerobic metabolism due to a reduction in the amount of oxygen required by the muscles during incremental exercises. The exercises that remain below this threshold are therefore called aerobic exercise, while those exceed this threshold are called anaerobic exercises. Some researchers report that anaerobic power and capacity are determinants of performance in sports which require speed, leap, quick acceleration or change of direction. Aerobic power is defined as the maximum rate of oxygen consumption $\left(\mathrm{MaxVO}_{2}\right)$ with the ability to produce aerobic energy during incremental exercise. Used as a synonym for "endurance", aerobic capacity is defined as the ability to maintain an exercise for a long time (Müniroğlu et al., 2012).

\section{Method}

\subsection{Participants}

This study was conducted with 33 male soccer players ( $n=8$ defense, $n=10$ midfield and $n=7$ forward) playing in different positions in Kastamonu amateur league. Players with no disability and with a training age of over 5 years were included in the study. The research is limited to the data obtained from these soccer players.

\subsection{Data Collection Tools}

First, the body mass index (BMI) values were calculated by measuring the height and weight of each player. Later, Illinois Agility Test, Yoyo Intermittent Recovery Test, $30 \mathrm{~m}$. Sprint Test and Running-Based Anaerobic Sprint Test (RAST) were conducted. All participants were informed about the test protocols before each test.

\subsubsection{Body Weight and Height}

Body height was measured with an accuracy of $0.1 \mathrm{~cm}$. using a Holtain (UK) stadiometer (Aslan \& Koç 2015). Participants took in and held a deep breath while keeping their head in the frankfort plane, and the vertical distance from the standing surface to vertex (top of the head) was measured (Gordon et al., 1988). Body weight was measured to the nearest 0.100 gr. via Tanita (Japan) body fat analyser. Players were weighed barefoot and in sportswear. Data regarding body weight and height were added to the personal information forms and then formulated.

BMI = Body weight $(\mathrm{kg}$.$) / Height \left(\mathrm{cm}^{2}{ }^{2}\right)$

The BMI values of all participants were obtained by dividing the weight in kilograms by the height in centimeters squared (Sevimli, 2008).

\subsubsection{Illinois Agility Test}

The Illinois agility test course is $10 \mathrm{~m}$. in length and $5 \mathrm{~m}$. in width with 3 cones spaced $3.3 \mathrm{~m}$. apart and placed on a straight line down the center of the area. The test consists of $40 \mathrm{~m}$. sprint and $20 \mathrm{~m}$. shuttle run with $180^{\circ}$ turns at each 10 meter. After test course is prepared, a two-gate photocell electronic timing system with a precision of 0.01 second is placed at start and finish line. Before they perform the test, participants need to be informed about the test and the test course, and then allowed to try it 3-4 times at a slow pace. After that, the participants do warm-up and stretching exercises for 5-6 minutes at a slow pace set by themselves. The participants in the sample group are asked to sprint ahead from the starting line of the test course, in a prone (front lying, face down) position, with their elbows flexed and hands placed at the sides of their chest, palms on the floor. Results are recorded in seconds. The test is administered once (Hazir et al., 2015). 


\subsubsection{Yo-Yo Intermittent Recovery Test (YYIRT)}

YYIRT is a test developed to measure the aerobic power of an athlete. The test is performed on a course of $25 \mathrm{~m}$. involving two markers that are set 20 meters apart and a third one $5 \mathrm{~m}$. apart to show the distance of recovery. Pre-test instructions for completing the test are clearly given to the athletes. The audio (signal) CD is played with a CD player (Sony CMT-FX 200, Japan), so the athletes are required to reach the $20 \mathrm{~m}$. marker at each audio signal given at regular intervals. The test starts at a speed of $10 \mathrm{~km} / \mathrm{second}$. Once instructed by the $\mathrm{CD}$, the athletes begin running $20 \mathrm{~m}$. in an increasing speed to a recorded audio signal, turn and run back to the starting line. When they get back, they have 10 seconds for an active recovery in the $5 \mathrm{~m}$. area behind the line. Each time they cover a distance of $40 \mathrm{~m}$. As the test progresses the amount of time they have to complete each pair of runs gets shorter, so they are required to run faster to keep pace with the audio. If the athletes fail to reach the $20 \mathrm{~m}$. marker in time, a warning is given and the test is completed at the third warning. The total distance covered by the athletes is recorded (Delicelioglu et al., 2014).

\subsection{4 $30 \mathrm{~m}$. Sprint Test}

$10 \mathrm{~m}$. and $30 \mathrm{~m}$. sprint performance of soccer players were measured using a photocell test system - Newtest 300 (Finland) test battery. Participants were instructed to start the test at the starting line $1 \mathrm{~m}$ behind the photocell when they were ready. $10 \mathrm{~m}$. and $30 \mathrm{~m}$. sprint performances of the players were measured by means of the photocells positioned at the distances of $10 \mathrm{~m}$. and $30 \mathrm{~m}$. Each participant was asked to perform the test twice at 3-minute intervals and the best score was recorded (Delicelioğlu et al., 2014).

\subsubsection{Running-Based Anaerobic Sprint Test (RAST)}

RAST (Repeated Sprint Ability test protocol- repeated anaerobic sprint test) involves six sprints over $35 \mathrm{~m}$. with a 10 second recovery between each sprint. The Newtest 300 (Finland) test battery was used to determine the repeated sprint ability of the athletes. Once the participants started running right behind the start-line photocell, the photocell began measuring and the performance values were recorded in seconds (Ceylan et al., 2016).

\subsection{Statistics and Data Analysis}

Statistical analysis was done with the SPSS 22.0 program, with the level of significance chosen as 0.05 and a confidence interval set at 95\%. Kolmogorov-Smirnov test was applied to test for a normal distribution. Since the data were normally distributed, the One-Way ANOVA was used in situations where more than two independent groups were compared.

\section{Results}

Table 1. Descriptive Statistics by Playing Positions

\begin{tabular}{lccc}
\hline Variables & \multicolumn{3}{c}{ Position } \\
\cline { 2 - 4 } & Defense & Mid-field & Forward \\
\hline Age (year) & $20 \pm 1.73$ & $20.09 \pm 1.97$ & $20.55 \pm 1.91$ \\
Height $(\mathrm{cm})$. & $1.80 \pm 1.75$ & $1.82 \pm 1.73$ & $1.78 \pm 0.06$ \\
Weight $(\mathrm{kg})$. & $66.91 \pm 12.51$ & $66.91 \pm 6.93$ & $70.55 \pm 7.87$ \\
Body Mass Index $\left(\mathrm{kg} / \mathrm{cm}^{2}\right)$ & $22.77 \pm 4.12$ & $22.20 \pm 2.01$ & $22.18 \pm 2.61$
\end{tabular}

Descriptive statistics of the soccer players participating in the study are shown in Table 1 . The number of observations for all parameters is 33 . 
Table 2. Comparison of Motor Characteristics in Soccer Players by Playing Positions

\begin{tabular}{|c|c|c|c|c|c|c|c|c|}
\hline Variables & & Position & $\mathrm{N}$ & $\mathrm{X}$ & $\mathrm{Sd} \pm$ & $\mathrm{F}$ & $\mathrm{p}$ & Difference \\
\hline \multirow{4}{*}{ Illinois Test (sec.) } & 1 & Defense & 11 & 15.46 & 1.06 & 9.827 & $0.001 *$ & $1-2$ \\
\hline & 2 & Midfield & 11 & 14.30 & 0.19 & & & $1-3$ \\
\hline & 3 & Forward & 11 & 14.53 & 0.31 & & & \\
\hline & 4 & Total & 33 & 14.76 & 0.81 & & & \\
\hline \multirow{4}{*}{ Yo-Yo Test (m.) } & 1 & Defense & 11 & 1705.45 & 600.8 & 0.176 & 0.840 & \\
\hline & 2 & Midfield & 11 & 1712.72 & 562.2 & & & \\
\hline & 3 & Forward & 11 & 1829.09 & 477.0 & & & \\
\hline & 4 & Total & 33 & 1749.09 & 534.8 & & & \\
\hline \multirow{4}{*}{$\mathrm{MaxVO}_{2}(\mathrm{ml} / \mathrm{kg} / \mathrm{min}$.) } & 1 & Defense & 11 & 51.18 & 4.03 & 0.854 & 0.436 & \\
\hline & 2 & Midfield & 11 & 53.25 & 3.44 & & & \\
\hline & 3 & Forward & 11 & 52.45 & 3.76 & & & \\
\hline & 4 & Total & 33 & 52.29 & 3.73 & & & \\
\hline \multirow{4}{*}{$30 \mathrm{~m}$. Sprint Test (sec.) } & 1 & Defense & 11 & 4.46 & 0.33 & 4.325 & $0.022 *$ & $1-2$ \\
\hline & 2 & Midfield & 11 & 4.15 & 0.11 & & & \\
\hline & 3 & Forward & 11 & 4.30 & 0.23 & & & \\
\hline & 4 & Total & 33 & 4.30 & 0.27 & & & \\
\hline \multirow{4}{*}{ RAST Maximal Power } & 1 & Defense & 11 & 1005.2 & 378.1 & 0.605 & 0.553 & \\
\hline & 2 & Midfield & 11 & 963.18 & 336.6 & & & \\
\hline & 3 & Forward & 11 & 1120.41 & 324.4 & & & \\
\hline & 4 & Total & 33 & 1029.63 & 342.8 & & & \\
\hline \multirow{4}{*}{ RAST Average Power } & 1 & Defense & 11 & 676.40 & 183.4 & 0.536 & 0.591 & \\
\hline & 2 & Midfield & 11 & 669.04 & 144.7 & & & \\
\hline & 3 & Forward & 11 & 735.94 & 168.3 & & & \\
\hline & 4 & Total & 33 & 693.80 & 163.8 & & & \\
\hline \multirow{4}{*}{ RAST Fatigue Index } & 1 & Defense & 11 & 16.99 & 5.03 & 0.088 & 0.916 & \\
\hline & 2 & Midfield & 11 & 16.15 & 5.72 & & & \\
\hline & 3 & Forward & 11 & 16.22 & 4.77 & & & \\
\hline & 4 & Total & 33 & 16.45 & 5.04 & & & \\
\hline
\end{tabular}

*p $<0.05$

Table 2 shows that there is a significant difference between the scores on Illinois Agility Test and $30 \mathrm{~m}$. Sprint Test $(\mathrm{p}<0.05)$, yet no significant difference was found between the players in regard to $\mathrm{MaxVO}_{2}(\mathrm{ml} / \mathrm{kg} / \mathrm{min}$.), Maximal Power, Average Power and Fatigue Index values obtained on Yo-Yo Test and RAST ( $>>0.05$ ). These findings indicate that the scores obtained by defenders on Illinois Test were lower than those of midfielders and forwards. It can therefore be suggested that midfielders and forwards are more agile than defenders. In addition, it is seen that defenders showed a better performance of $30 \mathrm{~m}$. Sprint Test than midfielders. It can be said that the midfielders can accelerate more quickly in short distances compared to the defenders.

\section{Discussion}

This study was conducted to compare the agility, sprint, anaerobic power and aerobic capacities of soccer players by their positions on the field of play. Participants were assigned to three groups as defenders, midfielders and forwards. The average age of the defenders was $20 \pm 1.73$ years, the average height was $1.80 \pm 1.75 \mathrm{~cm}$. and the average body weight was $66.91 \pm 12.51 \mathrm{~kg}$. and their average BMI was found to be $22.77 \pm 4.12$. The average age of the midfielders was $20.09 \pm 1.97$ years, average height was $1.82 \pm 1.73 \mathrm{~cm}$., average weight was $66.91 \pm 6.93 \mathrm{~kg}$. and the average BMI value 
was $22.20 \pm 2.01$. The average age of forwards was $20.55 \pm 1.91$ years, average height was $1.78 \pm 0.06 \mathrm{~cm}$., average body weight was $70.55 \pm 7.87 \mathrm{~kg}$. and the average BMI was $22.18 \pm 2.61$. Statistical analysis showed no significant differences in BMI values, Yo-Yo Test (m.), $\mathrm{MaxVO}_{2}$ (ml.kg.min-1), RAST Maximal Power, RAST Average Power and RAST Fatigue Index between defense, midfield and forward players ( $p>0.05$ ). Nevertheless, the Illinois Test (sec.) and $30 \mathrm{~m}$. Sprint Test (sec.) scores showed that defenders exhibited a better performance than midfielders and forwards. While our findings are consistent with some previous research, there are also other studies with contrary findings. Therefore, in this research, discussion and evaluation will be based on scientific evidence related to variables.

Delicelioğlu et al. (2014) found that the $30 \mathrm{~m}$. sprint time in young soccer players was $4.15 \pm 010$ (sec.) and the distance covered during YYIRT was 2052.0 \pm 3813.7 (m.). İmamoğlu et al. (2004) found that the average age of the male students from the School of Physical Education and Sports was $21.47 \pm 1.63$ years and the $30 \mathrm{~m}$. sprint time was $4.27 \pm 0.06$ seconds. Tokgöz and Dalkıran (2015) found the $30 \mathrm{~m}$. sprint time to be $4.30 \pm 0.15$ in 26 male soccer players with an average age of 19.65 3.45 years playing for different amateur soccer clubs in the city of Burdur.

In a study entitled "A Comparison of Motor Characteristics in Youth Soccer Players by Playing Positions" Yapıcı et al. (2016) reported that the average age of defenders was $19.16 \pm 0.83$ years, the average height was $1.75 \pm 5.84 \mathrm{~cm}$. and the average weight was $70.75 \pm 5.15 \mathrm{~kg}$. The average age of midfielders was $19.5 \pm 1.16$ years, average height was $180 \pm 4.53$ $\mathrm{cm}$. and the average weight was $74.16 \pm 6.76 \mathrm{~kg}$. The average age of forwards was $18.75 \pm 0.96$ years, average height was $1.76 \pm 5.66 \mathrm{~cm}$. and average weight was $74 \pm 4.72 \mathrm{~kg}$. The $30 \mathrm{~m}$. (sec.) sprint times were found to be $4.28 \pm 0.06 \mathrm{~m} / \mathrm{sec}$., $4.18 \pm 0.130 \mathrm{~m} / \mathrm{sec}$. and $4.29 \pm 0.070 \mathrm{~m} / \mathrm{sec}$. for defenders, midfielders and forwards, respectively. Their Yo-Yo Test results indicated that midfielders $(2838.33 \pm 279.01 \mathrm{~m}$.) and forwards $(2813.33 \pm 373.80 \mathrm{~m}$.) covered a greater number of distance compared to defenders that could run a distance of $2346.66 \pm 607.66 \mathrm{~m}$.

Köklü et al. (2009) conducted a similar study entitled "Comparison of Some Physical Fitness and Somatotype Characteristics of Young Soccer Players Regarding Their Playing Positions" and they found that defenders had an average age of $16.4 \pm 0.4$ years, an average height of $175.4 \pm 6.0 \mathrm{~cm}$., an average weight of $65.02 \pm 6.7 \mathrm{~kg}$. and an average BMI of $21.15 \pm 1.5$ midfielders had an average age of $16.2 \pm 0.3$ years, an average height of $171.4 \pm 4.6 \mathrm{~cm}$., an average weight of $63.3 \pm 5.9 \mathrm{~kg}$. and an average BMI of $21.52 \pm 1.62$, and forwards had an average age of $16.5 \pm 0.5$ years, an average height of $171.8 \pm 3.9 \mathrm{~cm}$., and average weight of $63.9 \pm 6.5 \mathrm{~kg}$. and an average BMI of 21.61 \pm 1.68 .

In his master's thesis "Determining the Somatotype Characteristics of Soccer Players in regard to Playing Positions" Döner (2011) found that the players participating in the study had an average age of $21.60 \pm 3.23$ years, with an average height of $174.95 \pm 6.10 \mathrm{~cm}$. for defense players, $173 \pm 4.55 \mathrm{~cm}$. for midfield players and $178 \pm 5.26 \mathrm{~cm}$. for forwards. The average BMI of the players was calculated to be $22.35 \pm 2.37$ for defenders, $21.32 \pm 2.32$ for midfielders and $22.53 \pm 1.99$ $\left(\mathrm{kg} / \mathrm{cm}^{2}\right)$ for forwards.

Ceylan et al. (2009) conducted a study with soccer players aged 14-19 years and found the following mean values: height=U15: $165.81 \mathrm{~cm} .$, U17: $177.78 \mathrm{~cm}$. and U19: $175.57 \mathrm{~cm}$.; BMI = U15: 20.00, U17: 21.20 and U19: 21.44 .30 $\mathrm{kg} / \mathrm{cm}{ }^{2}{ }^{2}$ sprint times were $4.36 \mathrm{~m} / \mathrm{sec}$., $4.29 \mathrm{~m} / \mathrm{sec}$. and $4.08 \mathrm{~m} / \mathrm{sec}$. respectively. Finally, the RAST scores were computed as follows: U15: $5.14 \mathrm{~m} / \mathrm{sec}$., U17: $4.91 \mathrm{~m} / \mathrm{sec}$. and U19: $4.92 \mathrm{~m} / \mathrm{sec}$. Arslan (2010) found $30 \mathrm{~m}$. sprint times to be $4.01 \pm 014 \mathrm{~m} / \mathrm{sec}$., $4.13 \pm 0.12 \mathrm{~m} / \mathrm{sec}$. and $4.14 \pm 0.16 \mathrm{~m} / \mathrm{sec}$. for defenders, midfielders and forwards respectively.

Performances of the players participating in the Yo-Yo Intermittent Recovery Test indicated that top-elite male soccer players playing matches at the international level and those doing highest intensity training had a higher performance level on the Yo-Yo test $(3420 \mathrm{~m}$.) than moderately trained soccer players $(2810 \mathrm{~m}$.) and players playing at a lower level $(2330 \mathrm{~m}$.) (Castagna et al., 2006). When the findings reported by Castagna et al. (2006) and those obtained in the current study are compared, it is seen that the performance scores achieved by midfielders and forwards are slightly higher than those of defenders.

Aslan and Koç (2015) reported the following $\mathrm{MaxVO}_{2}$ (ml.kg.min-1) values in regard to playing positions of soccer players: $50.90 \pm 9.66$ for goalkeepers, $48.98 \pm 4.4$ for defenders, $50.58 \pm 3.65$ for backs, $49.27 \pm 5.57$ for midfielders, $52.31 \pm 4.67$ for wingers and $48.33 \pm 5.52$ for forwards. They found that wingers had the highest value of $\mathrm{MaxVO}_{2}$ and forwards the lowest.

Sever (2013) investigated the $\mathrm{MaxVO}_{2}$ values in a group of young soccer players aged 16-17 years and found the mean $\mathrm{MaxVO}_{2}$ value of $46.362 \pm 5.708$ for defenders, $47.484 \pm 5.534$ for midfielders and $43.888 \pm 5.123$ for forwards. Midfielders showed a higher mean $\mathrm{MaxVO}_{2}$ than forwards.

Amiri et al. (2010) conducted a study with soccer players for agility performance using the Illinois Agility Test after different warm-up protocols consisting of static, dynamic, combined stretching, and no stretching. The test results obtained were $14.18 \pm 0.66$ seconds (no stretch), 14.90 \pm 0.38 seconds (static), 13.95 \pm 0.32 seconds (dynamic), and $14.50 \pm 0.35$ seconds (combined).

Açak et al. (2012) administered the Illinois Agility Test to Turkish Hearing Impaired Futsal Team consisting of male 
players who either cannot hear at all or can only hear using a hearing aid. The test results revealed a mean value of $15.74 \pm 0.49$ seconds for the players who cannot hear at all and $15.15 \pm 0.51$ seconds for those using a hearing aid.

\section{Conclusion}

The results of the study showed that forwards and midfielders were more agile than defenders, and midfielders were faster than defenders. As the distances soccer players cover vary according to their playing positions (defense, midfield and forward) together with the movements they perform on the pitch and the frequency of these movements, it will contribute to their performance to evaluate physical and physiological needs according to playing positions.

\section{References}

Açak, M., Karademir, T., Taşmektepligil, Y., \& Çalışkan, E. (2012). The examination of agility and visual reaction values of hearing-impaired futsal sportsmen. Selçuk University Journal of Physical Education and Sport Sceince, 14(2), 283-289.

Amiri-Khorasani, M., Sahebozamani, M., Tabrizi, K. G., \& Yusof, A. B. (2010). Acute effect of different stretching methods on Illinois Agility Test in soccer players. The Journal of Strength \& Conditioning Research, 24(10), 2698-2704. https://doi.org/10.1519/JSC.0b013e3181bf049c

Arslan, O. (2010). The Evaluation of Anaerobic Power Values and Sprint Performances of Football Players Playing in Different Positions. Master Thesis, On Dokuz Mayis University, Institute of Health Science, Department of Physical Education and Sport, Samsun.

Aslan, C. S., \& Koç, H. (2015). Comparing selected physical and motoric characteristics of Turkish amateur soccer players according to playing positions. CBU Journal of Physical Education and Sport Science, 10(1), 56-65.

Bencke, J., Damsgaard, R., Saekmose, A., Jørgensen, P., Jørgensen, K., \& Klausen, K. (2002). Anaerobic power and muscle strength characteristics of 11 years old elite and non-elite boys and girls from gymnastics, team handball, tennis and swimming. Scandinavian Journal of Medicine \& Science in Sports, 12(3), 171-178.

Castagna, C., Impellizzeri, F. M., Chamari, K., Carlomagno, D., \& Rampinini, E. (2006). Aerobic fitness and Yo-yo Continuous and Intermittent Tests performances in soccer players: A correlation study. Journal of Strength and Conditioning Research, 20(2), 320-326. https://doi.org/10.1519/R-18065.1

Ceylan, L., Demirkan, E., \& Küçük, H. (2016). Examination of sprint duration and repeated sprint level of soccer players in different age group. International Journal of Science Culture and Sport (IntJSCS), 4(1), 188-199. https://doi.org/10.14486/IntJSCS548

Deliceoğlu, G., Arı, E., \& Can, İ. (2014). The investigations of match actions and some performance parameters of young soccer players. Journal of Physical Education and Sport Science, 16(2), 57-69.

Döner, H. (2011). Determination of Somatotype Characteristics of Soccer Players with Respect to Their Positions (The Case of Diyarbakır). Doctoral Thesis, Selcuk University, Institute of Health Science, Department of Physical Education and Sport, Konya.

Göral, K., \& Göral, Ş. (2015). Examination of the relationship between sprint speed, vertical jump and strength parameters of female soccer players. MANAS Journal of Social Studies, 4(3), 116-123.

Gordon, C. C., Chumlea, W. C., \& Roche, A. F. (1988). Stature, recumbent length, and weight. Anthropometric standardization reference manual. Champaign: Human Kinetics Books, 3-8.

Harrison, G. G., Buskirk, E. R., Carter, J. L., Johnston, F. E., Lohman, T. G., Pollock, M. L., ... \& Wilmore, J. A. C. K. (1988). Skinfold thicknesses and measurement technique. Anthropometric standardization reference manual, 1988, 55-80.

Hazır, T., Mahir, Ö. F., \& Açıkada, C. (2010). Relationship between agility and body composition, anaerobic power in young soccer players. Hacettepe Journal of Sport Science, 21(4), 146-153.

İmamoğlu, O., Bostancı, Ö., \& Kabadayı, M. (2004). The researching of differences in 30 meters run and Margaria Kalamen Anaerobic Power on physical education and sports department students. SPORMETER Journal of Physical Education and Sport Science, 2(4), 147-154.

Inbar, O., \& Bar-Or, O. D. E. D. (1986). Anaerobic characteristics in male children and adolescents. Medicine and Science in Sports and Exercise, 18(3), 264-269. https://doi.org/10.1249/00005768-198606000-00002

Kearney, J. T., Rundell, K. W., \& Wilber, R. L. (2000). Measurement of work and power in sport. Exercise and Sport Science, 31-52.

Köklü, Y., Aşçı, A., Hazır, T., Alemdaroğlu, U., \& Açıkada, C. (2007). Relationships among different types of anaerobic 
power and capacity tests in soccer players. Turkish Journal of Sport Medicine, 42(3), 119-128.

Köklü, Y., Özkan, A., Alemdaroğlu, U., \& Ersöz, G. (2009). The comparison of some physical fitness and somatotype characteristics of young soccer players according to their playing positions. SPORMETER Journal of Physical Education and Sport Science, 7(2), 61-68.

Müniroğlu, A. Y. S., İşler, A., \& Akalan, C. (2012). The relationship between repeated sprint ability aerobic and anaerobic performance properties. SPORMETER Journal of Physical Education and Sport Science, 10(3), 95-100.

Özdemir, F. M. (2013). Relationship between Agility, Sprint, Power and Strength According to Different Age Groups in Youth Soccer Players. Master Thesis, Başkent Universisty Institute of Health Science, Department of Physical Education and Sport, Ankara.

Sever, O. (2013). Investigation of Physical Fitness Levels of Soccer Players According to Position and Age Variables. Master Thesis, Gazi University Institute of Health Science, Department of Physical Education and Sport, Ankara.

Sevimli, D. (2008). Investigation of the relationship between Body Mass Index and physical activity in adults. TAF Prev Med Bull, 7(6), 523-528.

Sheppard, J. M., \& Young, W. B. (2006). Agility literature review: Classifications, training and testing. Journal of Sports Sciences, 24(9), 919-932.

Sutton, N. C., Childs, D. J., Bar-Or, O., \& Armstrong, N. (2000). A nonmotorized treadmill test to assess children's short-term power output. Pediatric Exercise Science, 12(1), 91-100.

Tokgöz, M., \& Dalkıran, O. (2015). Examination of the effect some motoric and coordinative aspects on football technical skill in university male football team players. Journal of International Multidisciplinary Academic Researches, 2(1), $1-20$.

Yapıcı, A., Aydın, E., Çelik, E., \& Başkaya, G. (2016). The comparison of motoric characteristics of young soccer players according to their playing positions. Sporty View: Journal of Sport and Educational Science, 3(1), 49-60.

Young, W., Benton, D., \& John, P. M. (2001). Resistance training for short sprints and maximum-speed sprints. Strength \& Conditioning Journal, 23(2), 7-13.

\section{Copyrights}

Copyright for this article is retained by the author(s), with first publication rights granted to the journal.

This is an open-access article distributed under the terms and conditions of the Creative Commons Attribution license which permits unrestricted use, distribution, and reproduction in any medium, provided the original work is properly cited. 